\title{
THE APPLICATION OF MATHEMATICAL METHODS FOR STRATIGRAPHIC CORRELATION OF QUATERNARY DEPOSITS
}

\author{
A. Bitinas \\ Institute of Geology, 13 Sevcenkos str. Vilnius 2600, Republic of Lithuania
}

\begin{abstract}
The mathematical methods and computers for stratigraphic correlation of Quater nary deposits have been applied, because on account of various reasons, this problem can't be completely solved using only methods of biostratigraphy and geochronology. The stratigraph ic correlation of tills has been executed by using the results of lithological and geochemical in vestigations and mathematical - statistical methods. The application of the factor and cluster analysis have been most effective. Absolute data of the results of various laboratory investiga tions have been used for stratigraphic division of geological sections, while relative data (litho logical and geochemical coefficients or pair correlation coefficients) have been used for strati graphic correlation between the sections. Minimum number of samples necessary for statistic characteristics of each till has been obtained experimentally. Therefore the dependence of variation coefficient on the number of samples has been analyzed. The most reliable results of stratigraphic correlation of tills have been obtained using data of chemical (silicate) analysis. Key words : Till, Lithological, Geochemical, Statistical analysis, Cluster analysis, Factor analysis.
\end{abstract}

\section{INTRODUCTION}

Reliable correlation of Quaternary deposits is one of the most complicated problem in investigating of Quaternary thickness. In Lithuania it is especially ur gent in the zones of marginal deposits where thickness of Quaternary deposits reaches more than $200-250 \mathrm{~m}$. (Baltrunas and Bitinas, 1984). The Quaternary thick ness can be investigated only by boreholes. Quater nary deposits are frequently dislocated, folded, that's why tills and meltwater deposits of the same age often appear several times in one borehole. Interglacial de posits as well as deposits suitable for age determina tion by methods of absolute geochronology (radio carbon, amino-acids, thermo-luminescence dating, etc.) are found very seldom. So, stratigraphic correlation of the whole thickness of Quaternary deposits is carried out on the basis of correlation of tills. Up to now till gravel petrographic analysis was one of the most popular methods of stratigraphic correlation of tills in Lithuania (Gaigalas, 1979). But this method is not very precise and it requires much drill core, large gravel concentration in till, etc. It was clear that it is impossible to solve the problem of till correlation without mathematical methods. It turned out that most suitable methods for this purpose would be the method of D.A. Rodionov (1981) and factor or cluster analysis (Davis, 1973). Therefore, lately detailed lithological (granulometric, mineralogical analysis) and geochemical (chemical, spectrum analysis) in vestigations of till as well as mathematical - statistical processing of the obtained results have been applied in stratigraphic correlation of tills.

\section{STRATIGRAPHIC DIVISION OF TILLS IN SECTIONS}

At first the method of D.A. Rodionov was used for stratigraphic division of Quaternary tills in sec- tions. But according to this method it is difficult to understand if the distinguished boundary has a stratigraphic meaning or if it only separates crust of weathering, till floe, basal and ablation till, etc. (Fig. 1) It has been determined experimentally that factor or cluster analysis is more suitable for this purpose. Similar results have been obtained by both methods geological vertical section has been divided into rela tively homogeneous till layers or their parts (Fig. 2 ). Moreover, these methods enable to distinguish the so called anomalous samples, that were taken from floes, crust of weathering, etc. By the way, while di viding the section according to the results of factor analysis, it is expedient to analyze distribution of samples not only with respect to the 1 -st and $2-$ nd factors (as in Fig. 1) but also to the 1-st and 3 - rd as well as to the 2 -nd and 3 -rd factors.

\section{CORRELATION OF TILLS BETWEEN SECTIONS}

Correlation of the divided till layers between ver tical sections have been carried out using the same methods: factor and cluster analyses. But in this case, taking into account the specific character of till for mation, not the primary results of the analyses but the derivative parameters (lithological and geochemi cal coefficients or pair correlation coefficients) have been used (Table 1). The most reliable results have been obtained using first of all data of chemical anal ysis (Fig. 3) and data of spectrum and mineralogical analyses as well. Results of vertical section correlation serve as a basis in making geological profiles (Fig. 5). Certainly distinguished interglacial deposit layers are as control factors of trustworthiness of till correlation. 

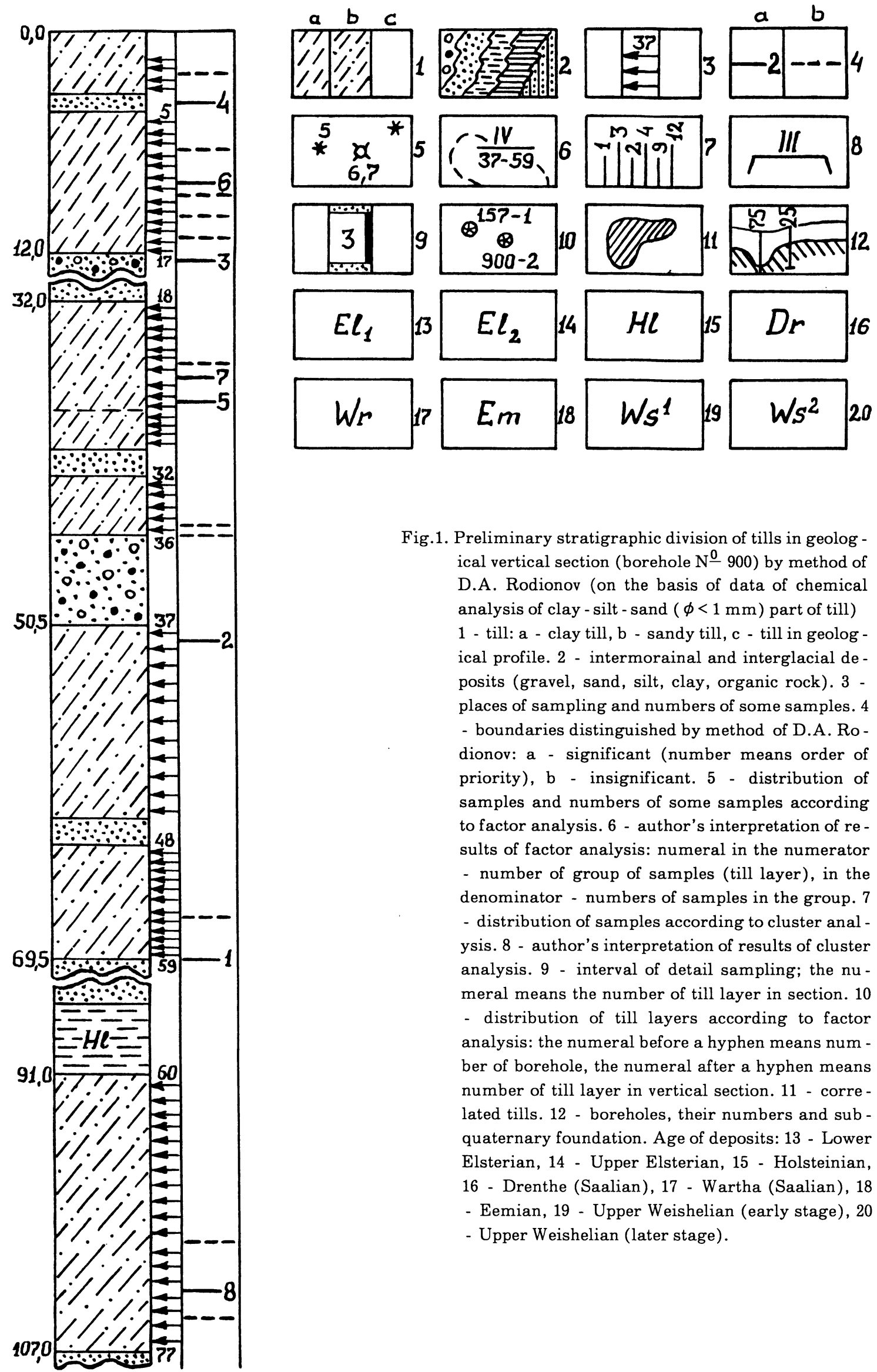

Fig.1. Preliminary stratigraphic division of tills in geolog ical vertical section (borehole $\mathrm{N}^{0} \mathbf{9 0 0}$ ) by method of D.A. Rodionov (on the basis of data of chemical analysis of clay - silt - sand ( $\phi<1 \mathrm{~mm})$ part of till) 1 - till: a - clay till, b - sandy till, c - till in geolog ical profile. 2 - intermorainal and interglacial de posits (gravel, sand, silt, clay, organic rock). 3 places of sampling and numbers of some samples. 4 - boundaries distinguished by method of D.A. Ro dionov: a - significant (number means order of priority), b - insignificant. 5 - distribution of samples and numbers of some samples according to factor analysis. 6 - author's interpretation of re sults of factor analysis: numeral in the numerator - number of group of samples (till layer), in the denominator - numbers of samples in the group. 7 - distribution of samples according to cluster anal ysis. 8 - author's interpretation of results of cluster analysis. 9 - interval of detail sampling; the nu meral means the number of till layer in section. 10 - distribution of till layers according to factor analysis: the numeral before a hyphen means num ber of borehole, the numeral after a hyphen means number of till layer in vertical section. 11 - corre lated tills. 12 - boreholes, their numbers and sub quaternary foundation. Age of deposits: 13 - Lower Elsterian, 14 - Upper Elsterian, 15 - Holsteinian, 16 - Drenthe (Saalian), 17 - Wartha (Saalian), 18 - Eemian, 19 - Upper Weishelian (early stage), 20 - Upper Weishelian (later stage). 
A

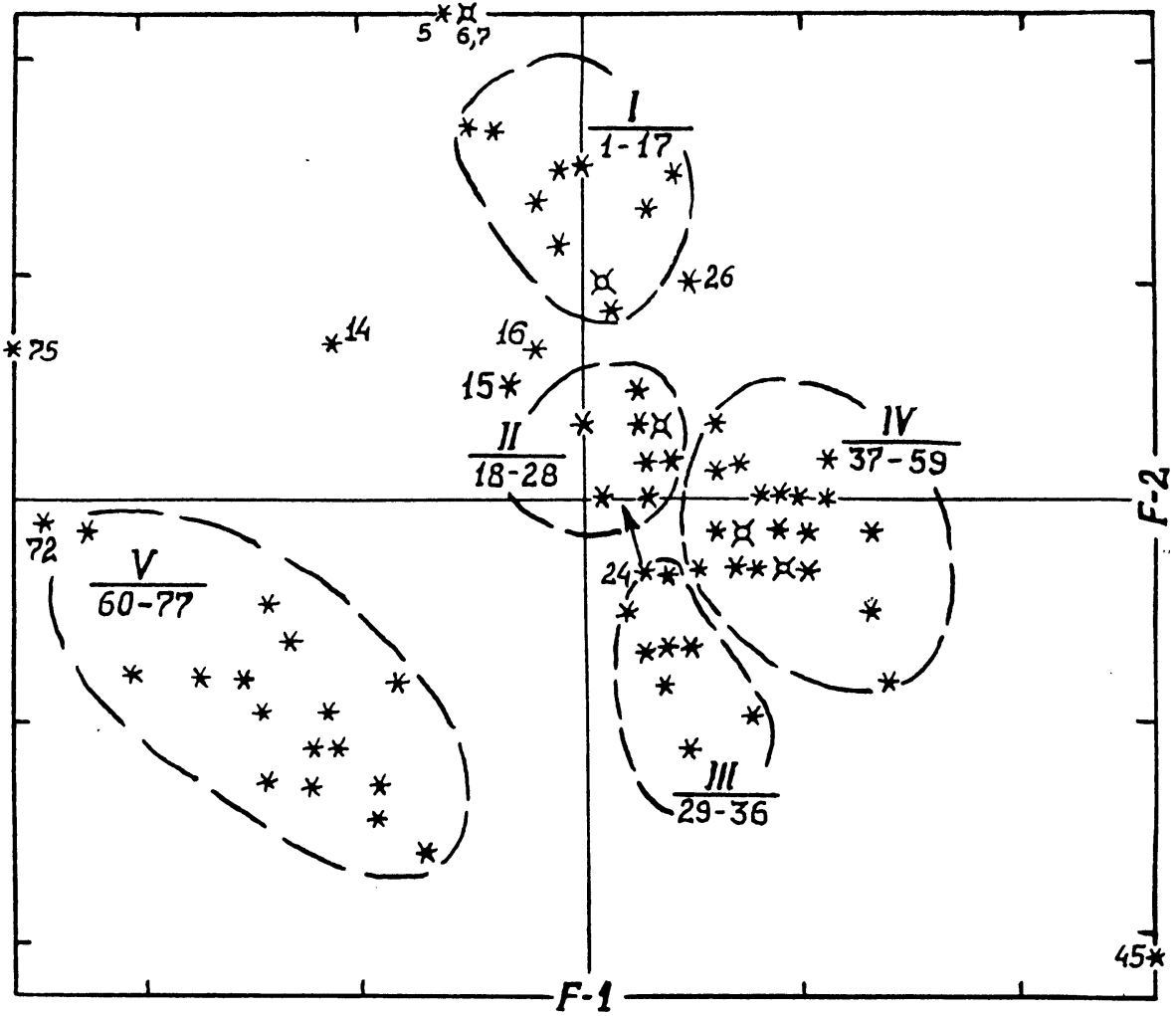

B

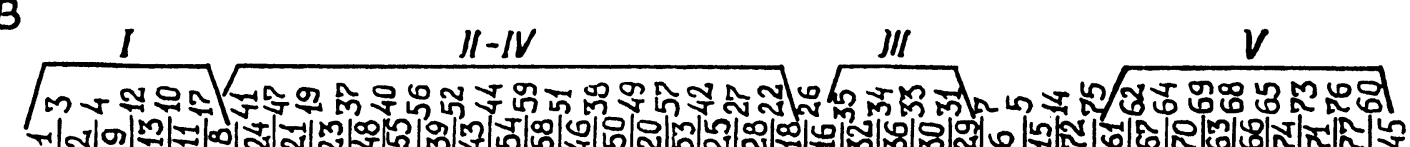

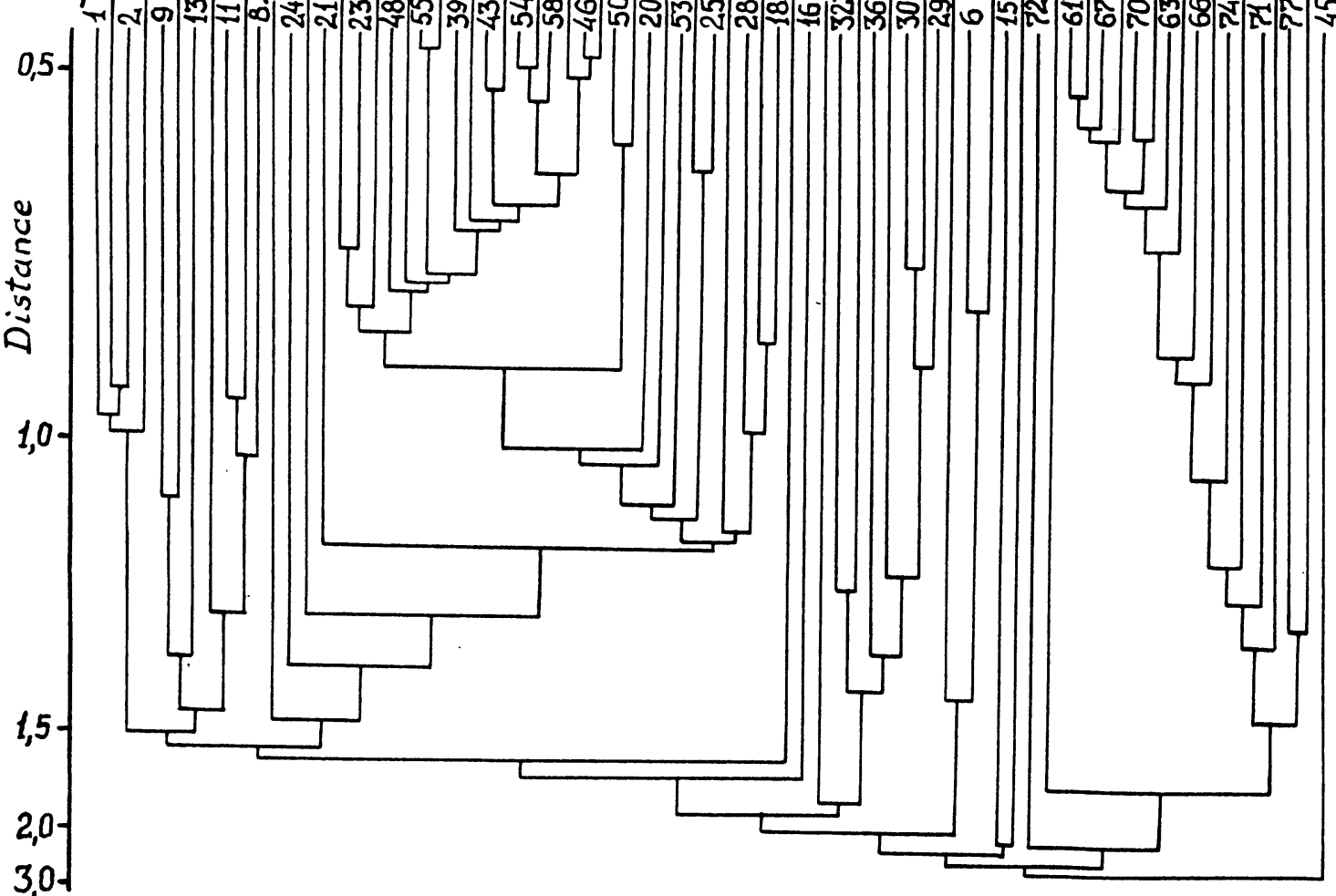

Fig.2. Interpretation of results of factor (A) and cluster (B) analyses (preliminary stratigraphic division of tills) carried out on the basis of chemical analysis of tills (borehole No 900). Conventional signs in Fig. 1. 


\section{PROBLEM OF TILL CORRELATION}

There are many factors which have serious influ ence on the results of till correlation: condition of drill core, quality of sampling, precision of an applied method, subjective mistakes of analyst. But there ex ists one problem that has an influence not only on the precision of correlation, but it also determines the ex pense of the method itself. This is a problem concern ing the amount of samples to be analyzed from a separate till layer of a separate section. It has been tried to solve this problem experimentally: dependence of the main statistic parameters of the results of various analyses on the amount of samples has been analyzed. The samples have been taken from a thick, rel- atively homogeneous till layer, distinguished accord ing to the above described method (Fig. 3, borehole No 911, till layer 4). Analyzing the dependence of variation coefficient on the amount of samples graph ically (Fig. 4) it is evident how this coefficient is ap proaching its theoretical meaning (constants). In this case (Fig. 4) it is considered that 15-17 samples for chemical analysis are sufficient to make a trustwor thy characteristics of a till layer in section. Thus it is possible to determine the minimum quantity samples (for various types of analysis) necessary for the char acteristics of a separate till layer in order to make a trustworthy correlation of sections.
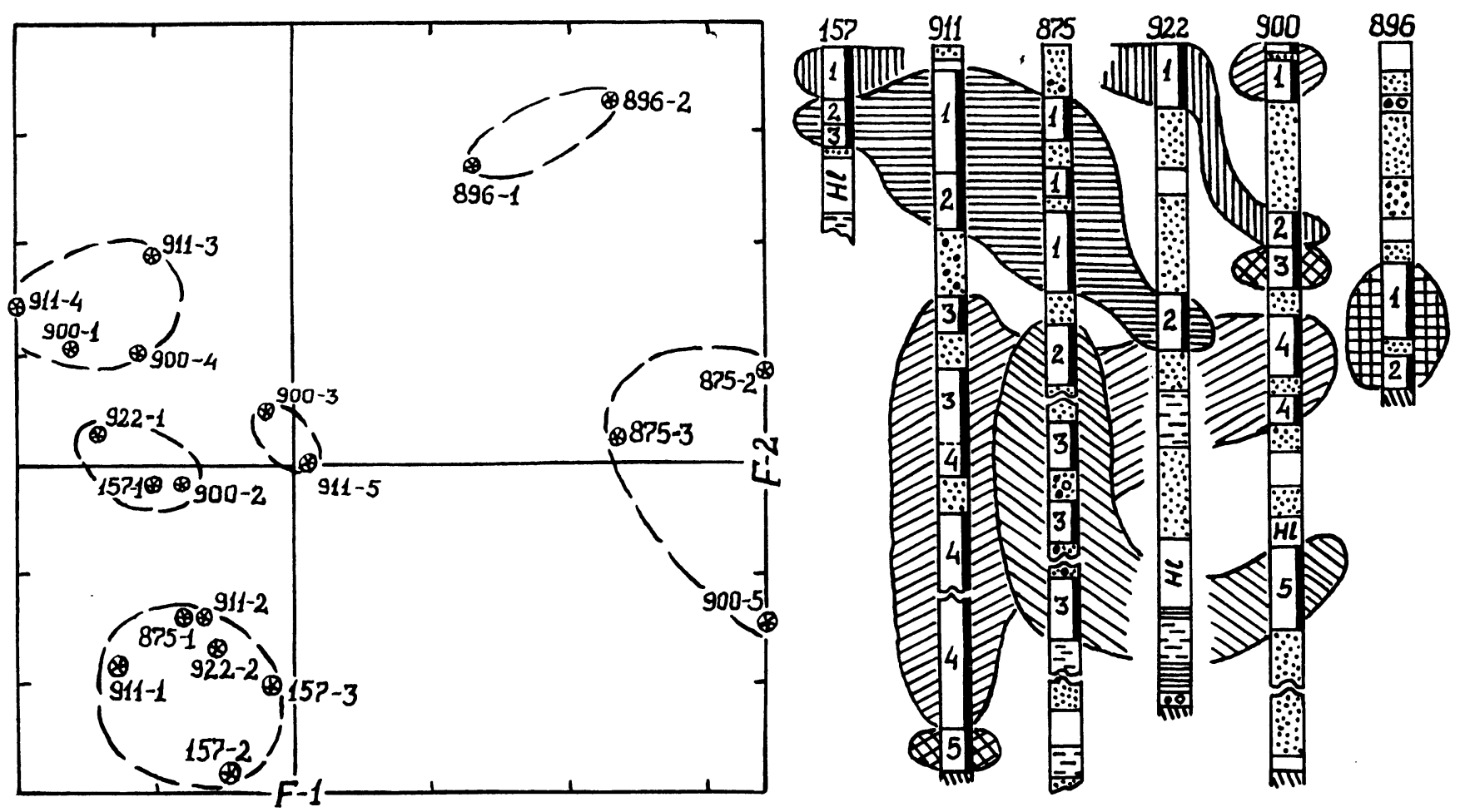

Fig.3. Grouping of till layers according to factor analysis. Factor analysis carried out on the basis of matrix of geochemical coefficients (Table 1). Conventional signs in Fig. 1.

Table 1.Geochemical coefficients of tills of some boreholes in North - East Lithu ania (Fig. 3)

\begin{tabular}{|c|c|c|c|c|c|c|c|c|c|c|c|c|c|c|c|c|c|c|c|c|}
\hline \multirow{2}{*}{$\begin{array}{l}\text { Number of } \\
\text { borehole } \\
\text { Number of } \\
\text { till layer }\end{array}$} & \multicolumn{3}{|c|}{157} & \multicolumn{5}{|c|}{911} & \multicolumn{3}{|c|}{875} & \multicolumn{2}{|l|}{922} & \multicolumn{5}{|c|}{900} & \multicolumn{2}{|c|}{896} \\
\hline & 1 & 2 & 3 & 1 & 2 & 3 & 4 & 5 & 1 & 2 & 3 & 1 & 2 & 1 & 2 & 3 & 4 & 5 & 1 & 2 \\
\hline $\mathrm{SiO}_{2} / \mathrm{Al}_{2} \mathrm{O} 3$ & 9.78 & 8.40 & 9.67 & 7.54 & 8.24 & 9.26 & 8.32 & 10.00 & 7.64 & 14.73 & 11.80 & 7.02 & 7.60 & 7.43 & 9.55 & 9.86 & 9.17 & 13.34 & 12.09 & 14.14 \\
\hline $\mathrm{SiO}_{2} / \mathrm{CaO}$ & 8. 62 & 10.19 & 14.13 & 7. 76 & 7.58 & 7.58 & 6.83 & 8.42 & 10.34 & 23. 30 & 16.75 & 7. 06 & 8.69 & 6.52 & 7. 35 & 7. 50 & 5. 99 & 17. 36 & 9.25 & 15.75 \\
\hline $\mathrm{TiO}_{2} / \mathrm{Al}_{2} \mathrm{O} 3$ & 0.02 & 0.02 & 0.03 & 0.04 & 0.04 & 0.04 & 0.03 & 0.03 & 0.03 & 0.05 & 0.04 & 0.04 & 0.05 & 0.03 & 0.03 & 0.03 & 0.03 & 0.05 & 0.05 & 0.06 \\
\hline $\mathrm{Al}_{2} 03 / \mathrm{K}_{2} \mathrm{O}$ & 2.68 & 3.03 & 2.96 & 2.78 & 2.78 & 2. 40 & 2.47 & 2.66 & 2.79 & 2.53 & 2.53 & 2.69 & 2.95 & 2.44 & 2.72 & 2.68 & 2.63 & 2.91 & 2.41 & 2. 38 \\
\hline $\mathrm{Al}_{2} 03 / \mathrm{Fe} 0$ & 11.53 & 8.45 & 11.16 & 9.26 & 8.07 & 8.94 & 9.01 & 8. 74 & 8. 16 & 8.45 & 8.85 & 10.14 & 7. 61 & 7.71 & 10.74 & 6.13 & 9.21 & 9.03 & 7.07 & 7.54 \\
\hline $\mathrm{Na}_{2} \mathrm{O} / \mathrm{Al}_{2} 03$ & 0.08 & 0.08 & 0.07 & 0.07 & 0.08 & 0.07 & 0.06 & 0.10 & 0.08 & 0.12 & 0.12 & 0.07 & 0.07 & 0.07 & 0.08 & 0.09 & 0.08 & 0.13 & 0.10 & 0.10 \\
\hline $\mathrm{CaO} / \mathrm{Al}_{2} 03$ & 1.14 & 0.82 & 0.68 & 0.98 & 1.09 & 1.22 & 1.22 & 1. 19 & 0.74 & 0.63 & 0.70 & 0.99 & 0.87 & 1.14 & 1.30 & 1.32 & 1.53 & 0.77 & 1.31 & 0.90 \\
\hline $\mathrm{K}_{2} \mathrm{O} / \mathrm{Na}_{2} \mathrm{O}$ & 4. 88 & 4. 19 & 4.60 & 4.84 & 4. 81 & 5.63 & 6.41 & 3.97 & 4. 49 & 3. 34 & 3.40 & 5.20 & 4.82 & 5.53 & 4.54 & 4. 30 & 4. 70 & 2. 70 & 4. 10 & 4. 19 \\
\hline $\mathrm{Pe} 203 / \mathrm{Fe} 0$ & 2. 73 & 1.86 & 2.96 & 2.23 & 1.93 & 2.00 & 2.12 & 1.93 & 1. 97 & 1.89 & 2.02 & 2.63 & 1.54 & 1.95 & 2.98 & 1.20 & 2.20 & 1. 75 & 1.41 & 1.20 \\
\hline $\mathrm{CaO} / \mathrm{Mg} 0$ & 2.21 & 2.54 & 2.26 & 2.47 & 2.83 & 2.20 & 2.03 & 2.49 & 2.15 & 2.69 & 2.50 & 1.96 & 2.48 & 2.13 & 2. 33 & 2.44 & 2.24 & 3.07 & 2.46 & 2.06 \\
\hline $\begin{array}{l}\text { Amount of } \\
\text { samples }\end{array}$ & 12 & 7 & 7 & 12 & 10 & 13 & 21 & 9 & 14 & 9 & 24 & 7 & 14 & 13 & 11 & 8 & 21 & 18 & 16 & 15 \\
\hline
\end{tabular}

Table 1.Geochemical coefficients of tills of some boreholes in North - East Lithu ania (Fig. 3) 


\section{CONCLUSIONS}

The technological process of till stratigraphic cor relation contains a few cycles of data treatment by mathematical - statistical methods and successive ge ological interpretation: detailed sampling of tills $\longrightarrow$ laboratory analyses (mineralogical, chemical, spectrum, etc.) $\longrightarrow$ selection of mathematical - statistical methods for data processing $\longrightarrow$ data processing (fac tor, cluster analysis) $\longrightarrow$ preliminary stratigraphic division of tills in the geological vertical sections $\longrightarrow$ calculation of characteristics for each distinguished till layer (mineralogical or geochemical coefficients, coefficients of pair correlation, etc.) $\longrightarrow$ grouping of till layers between sections (factor, cluster analysis) $\longrightarrow$ final stratigraphic division of geological vertical sections and making of geological profiles.

The most precise results of stratigraphic correla tion of tills have been obtained using data of chemical (silicate) analysis.

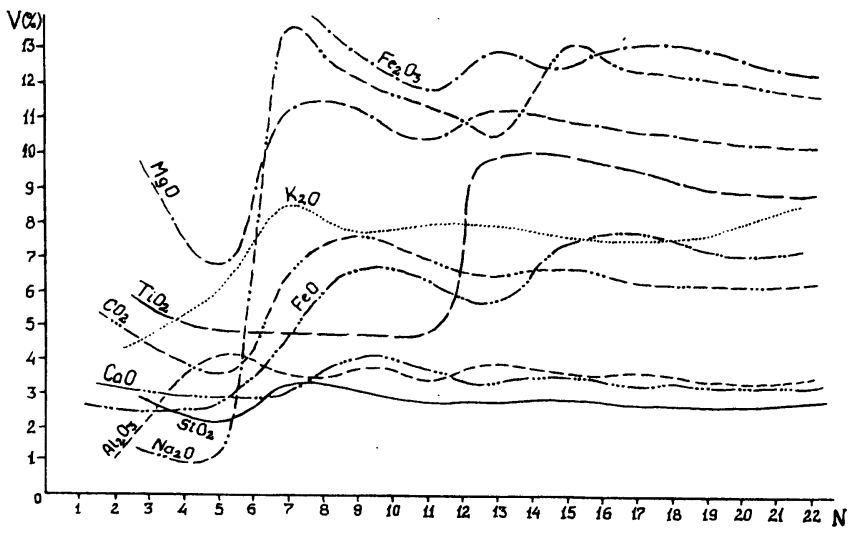

Fig.4. Dependence of variation coefficient $(\mathrm{V})$ on the num ber of samples $(\mathrm{N})$. Results of chemical analysis of relatively homogeneous till layer (Fig. 3, borehole No 911, till layer 4).

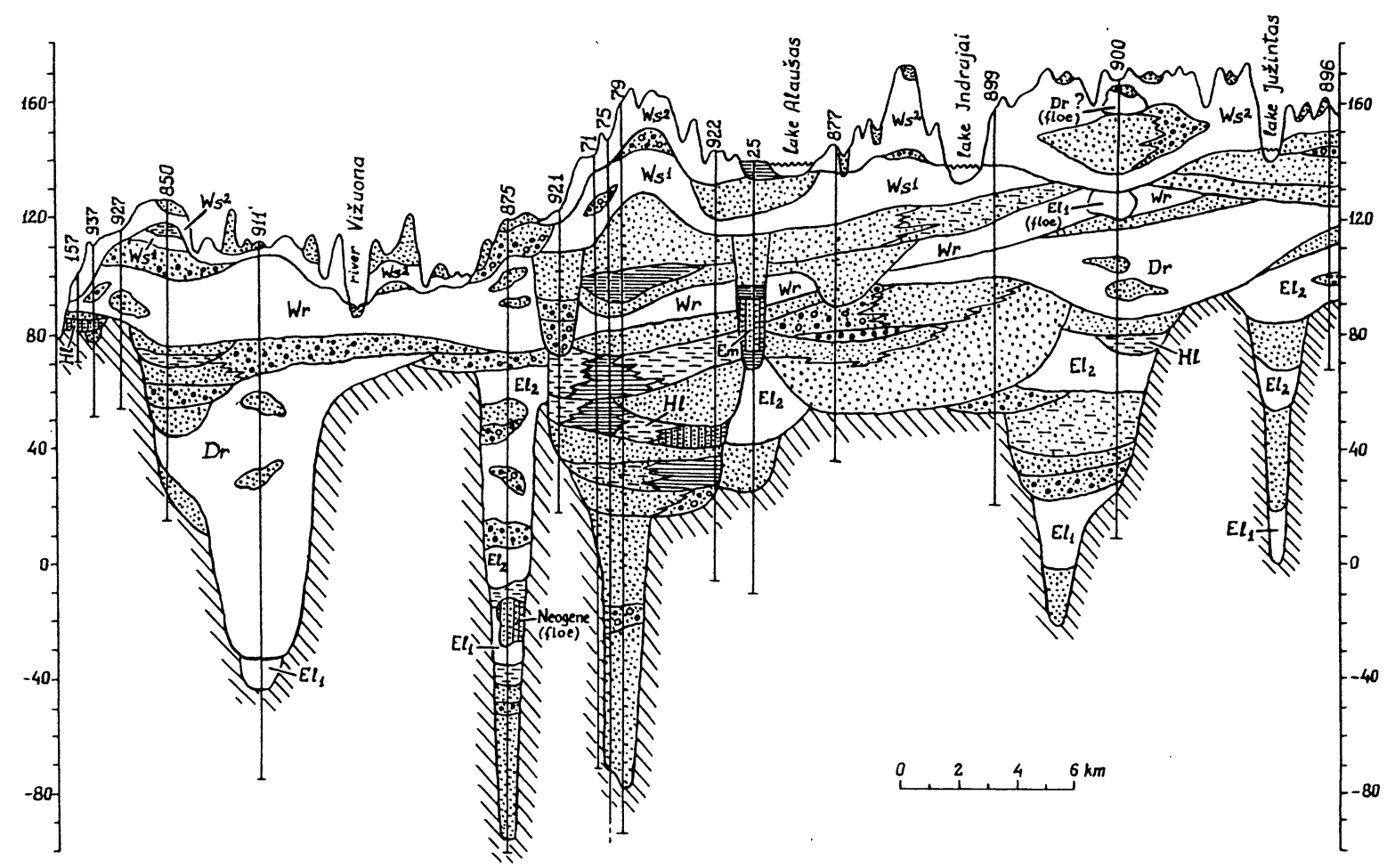

Fig.5. Geological profile of Quaternary thickness in North - East Lithuania carried out on the basis of results of computer stratigraphic correlation of tills. Conventional signs in Fig. 1.

\section{ACKNOWLEDGMENT}

I sincerely thank Ms. R. Zinkuté for help in statis tical execution of data and Ms. N. Bitiniene who cor rected the English text.

\section{REFERENCES}

Baltrünas, V. A., and Bitinas, A. K. (1984) Peculi arities of structure of Quaternary deposits in South-East Lithuania. Paleogeography and stratigraphy of the Quaternary period in Baltic and adjacent areas. pp. $74-80$, Vilnius. (in Rus sian)
Davis, J.C. (1977) Statistics and data analysis in ge ology. Mir, Moscow, 571 pp. (in Russian)

Gaigalas, A. (1979) Glacio-sedimentation cycles of Pleistocene of Lithuania. Mokslas, Vilnius, $98 \mathrm{pp}$. (in Russian)

Rodionov, D. A. (1981) Statistical solutions in geolo gy. Nedra, Moscow, 231 pp. (in Russian) 